\title{
Enhancing Peer Acceptance of Children with Learning Difficulties: Classroom Goal Orientation and Effects of a Storytelling Program with Drama Techniques
}

Yin-kum Law, $\mathrm{PhD}^{1}$, Shui-fong Lam, $\mathrm{PhD}^{2}$, Wilbert Law, $\mathrm{PhD}^{2}$, Zoe W. Y. Tam, $\mathrm{PhD}^{1}$ The University of Hong Kong

\author{
Author Note \\ ${ }^{1}$ Division of Language and Literature, Faculty of Education, University of Hong Kong \\ ${ }^{2}$ Department of Psychology, University of Hong Kong
}

This research was supported by the Research and Conference Grants at the University of Hong Kong.

The authors would like to thank Man-ho Lai, Daisy Yam, Man-jing So, Sin-ying Leung, Hau-yin Yik, Man-lai Pan, Sin-ling Kwok, and Tsa-yan Lo for their assistance to this study.

Correspondence concerning this manuscript should be addressed to Shui-fong Lam, Department of Psychology, the University of Hong Kong, Pokfulam Road, Hong Kong. E-mail: lamsf@hku.hk. Tel: (852) 3917-2388 


\begin{abstract}
Peer acceptance is an important facilitator for the success of inclusive education. The aim of the current study is twofold: (1) to examine how classroom goal orientation is associated with children's acceptance of peers with learning difficulties; and (2) to evaluate the effectiveness of a storytelling program with drama techniques on children's acceptance of peers with learning difficulties. The participants were 86 Grade 3 students from a Hong Kong primary school, randomly assigned to an experimental group $(n=45)$ and a control group $(n=41)$. The findings indicated that the more the students perceived that their classroom was performance-approach oriented, the less they would accept their peers with learning difficulties in doing things together. After the intervention, the students in the experimental condition, compared to their counterparts in the control group, were more likely to render financial assistance and have affective acceptance to their peers with learning difficulties.
\end{abstract}

Keywords: inclusive education; peer acceptance; storytelling; drama; classroom goal orientation 


\section{Enhancing Peer Acceptance of Children with Learning Difficulties: Classroom}

\section{Goal Orientation and Effects of a Storytelling Program with Drama Techniques}

To provide equal learning opportunities for students with special education needs (SEN), many countries have implemented inclusive education and placed them in general education classrooms (G. Lindsay, 2007). Intensive contacts between these students and their peers without SEN may have a positive impact on their social and emotional development (Koster, Nakken, Piji, \& van Houten, 2009). Some research has shown that both students with and without SEN benefit from being part of an inclusive class (e.g., de Boer, Piji, Minnaert, \& Post, 2014). However, the positive effects of inclusive education are not guaranteed if the students with SEN are rejected by their peers (G. Lindsay, 2003; Siperstein, Norins, \& Mohler, 2007).

Among the students with SEN, those with learning difficulties may experience a unique challenge in earning peer acceptance. Unlike students with physical and sensory handicapping conditions, the disabilities of these students are invisible. They may be students with mild intellectual disability and dyslexia. Their disorder may be in one or more of the basic psychological processes pertaining to visual, auditory, motor or language processing (Nowicki, 2003; Vaughn \& Hogan, 1994). While these psychological processes are covert, their difficulties in learning are overt (Salend, 2011). The invisibility of their disabilities may invite misunderstanding from their teachers and peers who may think that they are lazy or unmotivated. In addition, these students may lack the social skills to maintain positive relationships with their peers (Frostad \& Piji, 2007). Research has shown that these students might be rejected, neglected and isolated by their peers (Koster et al., 2009; Piji \& Frostad, 2010; Siperstein, Parker, Norins, \& Widaman, 2007). To help these students, it is important 
to understand the factors that contribute to peer acceptance, an indispensable component in the success of inclusive education.

\section{Conditions for the Success of Inclusive Education}

Salend (2011) listed five conditions for effective inclusion: (1) equal access for students with disablities to a general education curriculum; (2) teachers using inclusive practices that promote acceptance and equality; (3) teachers having positive attitudes to students with disabilities and using various teaching approaches to cater for individual differences; (4) students being taught to respect and value individual diversity, and students engaging in collaborative learning activities; (5) establishment of a learning community that emphasizes acceptance and belonging. Among the above conditions, peers' and teachers’ positive attitudes deserve special attention.

Simply implementing inclusive education and providing opportunities for social participation are not enough. To implement inclusive education successfully, teachers and peers need to show support, recognition and empathy to students with SEN (Obiakor, Harris, Mutua, Rotatori, \& Algozzine, 2012). Past research has shown that peers' positive attitudes can help students with disabilities become integrated in regular classrooms (de Boer, Piji, \& Minnaert, 2012; Georgiadi, Kalyva, Kourkoutas, \& Tsakiris, 2012). Past research has also shown that teachers’ positive attitudes can help students with learning difficulties achieve academic and social success (Brady \& Woolfson, 2008; Siperstein, Norins et al., 2007). Their support for inclusion can increase the chances of these students being accepted by their peers (Forlin \& Cole, 1994; Norwich \& Ylonen, 2013). Teacher support can be direct and explicit, such as the use of various teaching approaches to cater for individual differences (Salend, 2011). It can also be indirect and implicit, such as the cultivation of classroom goals.

\section{Classroom Goal Orientation and Peer Acceptance}


Students with a performance goal orientation focus on outperforming others and seeking positive evaluation of their performance (Poortvliet \& Darnon, 2010). Therefore, classrooms with a strong performance goal orientation are competitive and may not be conducive to peer acceptance of students with disabilities. Competition would decrease helping behaviors in students (Benninga et al., 1991). The decrease is expected because students in competitive classrooms are more likely to experience pressure to focus on their performance relative to their peers (Lam, Yim, Law, \& Cheung, 2004). However, there is little research on the relation between classroom goal orientation and students' acceptance of their classmates with learning difficulties. Despite the dearth of research in this area, a few studies on intellectual disability may provide some clues about the possible associations between classroom goal orientation and peer acceptance. For instance, Siperstein, Parker, Norins, and Widaman (2011) found that the youth in their study believed that students with intellectual disability could not carry out complicated tasks and therefore they were not willing to work with them. In a classroom with a performance goal orientation, it is very likely that students may feel that their peers with learning difficulties would be a liability to their academic performance in group work.

S. Lindsay and Edwards (2013) argued that disability awareness interventions for children should be context specific and take societal customs into account. The study presented here was conducted in Hong Kong, a Chinese society. Chinese classrooms are known for their competitiveness and emphasis on academic performance (Watkins \& Biggs, 1996). There is strong performance goal orientation in Chinese classrooms. For many Chinese students, the purpose of engaging in academic work in the classroom is to out-perform others or not to perform worse than others in competition (Liu, 2003). Hong Kong classrooms are typical Chinese 
classrooms with a very competitive climate. Inclusive education in Hong Kong has been facing many challenges since the Government launched it in 1997. One of the biggest challenges is the pressure that arises from keen competition (Poon-McBrayer, 2004). To promote peer acceptance of students with disabilities in Hong Kong, it is therefore important to first ascertain how classroom goal orientation is related to Chinese students' acceptance of their peers with learning difficulties. To investigate the role of classroom goal orientation in peer acceptance is one of the objectives of the current study.

\section{Interventions for Peer Acceptance}

A considerable number of studies has indicated that students' acceptance of peers with SEN can be enhanced through interventions (de Boer et al., 2014). Siperstein et al. (2011) pointed out that there were three common intervention approaches to changing students' attitudes: (1) teacher-directed instruction about disabilities; (2) structured contact through third-party facilitation such as cooperative groups and buddy programs; and (3) combined instruction with structured contact.

To increase children's positive attitudes towards peers with SEN, children literature is a less noticed but important tool in intervention (Martinez \& Carspecken, 2006). Although it is not explicitly included in the review of Siperstein et al. (2011), its potential as an intervention tool can be enormous, particularly when the text is illustrated with pictures. Pictures can reduce students’ cognitive load, and consequently, increase their understanding of the text (Schwamborn, Thillmann, Opfermann, \& Leutner, 2011). Well-written picture books can help younger children develop multiple perspectives and thus increase their understanding of others (Morgan, 2009). Picture books of stories about children with disabilities may be a useful tool for teacher-directed instructon about disabilities, the first approach of intervention 
reviewed by Siperstein et al. (2011). In fact, Ostrosky, Mouzourou, Dorsey, Favazza, and Leboeuf (2015) have advocated using childeren's books to support positive attitudes among young children toward peers with disabilities. They argued that through book-reading and discussions, teachers can promote disability awareness in their classrooms.

\section{Storytelling with Drama Techniques as Means of Intervention}

Telling a compelling story can be an effective approach to persuading people (Rutland \& Killen, 2015) because a story does not only provide information but also arouse listeners' emotions and energy (McKee, 2003). When learners associate their learning with emotion, they can have better learning retention (Dunn \& Stinson, 2012; Winston, 1999). McDrury and Alterio (2003) pointed out that storytelling is a highly reflective learning activity which approximates to real-life experiences. They argued that storytelling stimulates students' emotions and prompts students to reflect on personal experiences. Using a similar argument, Shuman (2006) posited that storytelling opens up the possibility of empathy.

Similar to storytelling, drama is highly recommended as an intervention tool because it can also arouse students' emotions and promote their empathy (Edmiston, 2000; Winston, 1999). By participating in a drama activity, students are being immersed in the characters' world. Smiley (2005) explained that an empathetic personality can be created if one places oneself in other people's shoes. The use of drama can change students' views of others by role playing and by adopting others' perspectives. In addition, Kardash and Wright (1986) argued that drama can contribute positively to the development of moral reasoning because of its student-centered approach of instruction. In student-centered instruction, students can learn in a more accepting and open atmosphere than they would in teacher-led 
instruction. Therefore, students may be more open to new ideas and attitudes, including those related to acceptance of peers with disabilities.

Read (2008) indicated that storytelling and drama share many common features. Both build on children’s capacity for play, deal with significant issues, involve multiple intelligences, appeal to different learning styles, suspend norms and identity temporarily but also set rules and directions for a particular context. If these two tools were combined, they would have ample potential in interventions by engaging students' interest, attention and imagination. To act upon the stories being told, students are no longer passive listeners. Instead, they actively participate in the stories. Baldwin and Fleming (2003) pointed out that children can be supported by being invited to engage actively, collectively and emotionally in the story world, not only with the characters but as the characters. Empathy and acceptance are cultivated when students try to understand themselves and others in role playing.

Despite the potential of storytelling and drama in moral education, there are only a limited number of empirical studies that examined their effectiveness on peer acceptance of students with disabilities (S. Lindsay \& Edwards, 2013). Martinez and Carspecken (2006) conducted a storytelling program of six lessons over five weeks with Grade 3 and Grade 4 students. Although drama techniques were not used, the findings showed that after the program, the children in the experimental condition showed a more favorable attitude towards peers with SEN than the chidren in the control condition. de Boer et al. (2014) also conducted a storytelling program, with 22 kindergarten children, of six lessons over three weeks. The findings indicated immediate attitude changes in the students. Despite both studies having used storytelling as intervention tool and obtaining encouraging results, they did not make use of drama techniques. In addition, they did not investigate how classroom goal 
orientation is related to attitudes, nor did they go beyond self-reported attitudes for behavioral measures of attitudinal changes.

In the current study, we combined storytelling and drama in an intervention to change students' acceptance towards their peers with learning difficulties. To add to the emerging literature on intervention programs for peer acceptance, the current study addressed two objectives: First, to examine how classroom goal orientation is related to students’ acceptance of peers with learning difficulties; and second, to evaluate the effectiveness of a storytelling program with drama techniques on students' acceptance of peers with learning difficulties. It is expected that performance goal orientation is negatively associated with students' acceptance of peers with learning difficulties. It is also expected that the intervention program will have positive effects on students' acceptance of peers with learning difficulties.

\section{Methods}

\section{Design}

The design of the current study was a randomized control trial. Students in both the experimental condition and the control condition attended a four-day story storytelling program. While the students in the experimental condition studied stories about children with learning difficulties, students in the control condition studied stories about environmental protection.

\section{Participants}

The participants were 86 Chinese Grade 3 students from a Hong Kong primary school. Their average age was 8.43 years $(S D=.50)$; 45 of the students were boys. Parental consent was obtained before the study was commenced; the consent rate was 95.6\%. The students were randomly assigned to the experimental group $(n=45)$ and the control group $(n=41)$. There was no significant difference between the two 
groups in terms of gender $\left(\chi^{2}=.04, d f=1, p=.85\right)$, the number of students identified by the homeroom teachers as having learning difficulties $\left(\chi^{2}=1.15, d f=1, p=.28\right)$, the school examination scores in that academic year $(t=.16, d f=84, p=.87)$, and the conduct grade reported by the homeroom teachers $(t=.43, d f=84, p=.67)$.

\section{Procedures}

The storytelling program was conducted four days in a row as extra-curricular activities before the summer vacation. The school had four classes of Grade 3 students. To meet the requirements of a randomized control trial, the students from these four classes were reshuffled and assigned randomly to four new classses, with two classes in each condition. The storytelling program was conducted concurrently in these four classrooms for two hours every day. In each classroom, the program was conducted by a female teacher who had just completed her training in a post-graduate diploma program in Chinese Language education. Their average age was 23.25 years ( $S D$ $=.50$ ). All teachers received a week of intensive training in conducting the storytelling program with drama techniques. The training consisted of 10 three-hour workshops with discussion, demonstration, and practice. The teachers were required to be familiar with the lesson plans and the techniques involved. They took turn to practise teaching and received feedback from their supervisors and peers.

Three weeks before the program, the students completed a questionnaire about the goal orientation of their original classrooms and their attitudes towards peers with learning difficulties. The goal orientation of the classroom reflected the level of perceived competitiveness of the classroom (Murayama \& Elliot, 2012). When competition is keen and social comparison is salient, the classroom tends to have a performance-approach and performance-avoidance goals (Midgley et al., 2000). Both goals are closely related to performance. While performance-approach goals focus on 
outperforming others, perofrmance-avoidance goals focus on not performing worse than others.

A day after the program, the students completed the same questionnaire without the questions on classroom goal orientation but with new questions on teaching evaluation and the intention to make a donation for the cause of helping students with learning difficulties. The students completed the pre- and post-program questionnaires in their classrooms without the presence of their teacher but under the guidance of a research assistant who was blind to the conditions and hypotheses. All the items in the questionnaires were in Chinese and a back-translation procedure (Brislin, 1970) was adopted for the scales that were originally in English. The items were read aloud to the students by the research assistant. The students were told that there was no right or wrong answer to the questions and that they could answer according to their thoughts or feelings.

\section{Storytelling Program with Drama Techniques}

The students in each classroom read one picture book together every day. The two classes in the experimental condition read picture books on children with learning difficulties whereas the two classes in the control condition read picture books on environmental protection (see appendix for booklist). The pictures and the text of the stories were projected on a big screen in the center of the classroom and the students sat in two semi-circle rows in front of it.

The four stories in the experimental condition all start off with introducing the protagonists as having certain learning difficutlies. The stories then describe how the protagonists do poorly in school. In some of the stories, the protagonists are also rejected or bullied by their peers. As a result, they often feel lonely and dejected. Later on, the stories show that with some assistance from their teachers and peers, children 
with learning difficulties can perform adequately. In addition, all stories emphasize that children with SEN, just like everyone, have certain strengths and weaknesses. They would also like to make friends and could be nice companions.

The teachers taught those stories according to a detailed lesson plan that employed many techniques in drama education. These techniques included "teacher in role,” "hot-seating,” “still-image,” "thought-tracking,” “conscience alley,” and "mantle of the expert" (Neelands \& Goode, 2000). Different techniques have their unique functions: "hot-seating” enables students to ask questions to someone who role-plays the character and sits in the "hot-seat"; "still-image” helps students to believe in the context; "teacher in role” and "mantle of the expert” serve as narrative actions to motivate students to think and talk; "thought-tracking” and "conscience alley” provide a safe and open space for students to enage in self-reflection.

The above drama techniques are useful teaching tools to promote moral education because students are being encouraged to discuss and to express their opinions both in-role or being themselves in the drama context. Students feel more comfortable to approach sensitive issues than in ordinary classes since there are no right or wrong answers. Besides, students' concentration and awareness of the characters' situation can be stimulated. Since students have to give appropriate responses or help the character to solve problems during the drama activities, they must learn to adopt other people’s perspectives.

In the current study, teachers interacted with students by asking questions during the storytelling session. Students were invited to explore the characters' feelings and motivations of certain behaviors. They were also invited to role play the characters, to help the characters solve problems, and to guess the ending of the stories. For example, when studying the story book "Hudson hates school," students played the 
role of Hudson, a little boy who hated going to school because he was afraid of getting low marks and being an object of ridicule by others. Students needed to think and talk in Hudson's role as well as to ask and answer questions that would be appropriate to Hudson's situations. By doing so, students would be able to know more about Hudson's behaviors and feelings.

\section{Measures}

Classroom performance-approach goals. Six items adapted from the Classroom Performance-Approach Goal Structure Scale (Midgley et al., 2000) were used to measure how much the original classroom of the students emphasized out-performing others. The students were asked to indicate their agreement to these six statements (e.g., "In our class, it’s important to out-perform others”) on a 4-point scale ( 1 = strongly disagree, $4=$ strongly agree). The alpha coefficient of the scores of these six items was .71. The average of the scores was used to indicate how much the students perceived that their classrooms were performance-approach oriented.

Classroom performance-avoidance goals. Six items adapted from the Classroom Performance-Avoidance Goal Structure Scale (Midgley et al., 2000) were used to measure how much the original classroom of the students emphasized on avoiding to perform worse than others. They indicated their agreement to these six items (e.g., “In our class, it’s important that you don’t make mistakes in front of everyone”) on a 4-point scale ( 1 = strongly disagree, $4=$ strongly agree). The alpha coefficient of the scores of these six items was .71. The average of the scores was used to indicate how much the students perceived that their classrooms were performance-avoidance oriented.

Behavioral acceptance. This was measured by the Behavioral Intention Scale (Siperstein, Parker et al., 2007). The 12 statements in this scale presented various 
activities which the students might do together with peers with learning difficulties (e.g., "work together with them on a project in class”). To help the students understand the meaning of learning difficulties, the following instructions were given: "In school some children may learn slower than the others. Very often they don't understand what the teacher teaches and cannot do their school work well. They cannot catch up with the progress of their classmates. They are the students with learning difficulties. We would like to know whether you will do the following activities with them.” The students were asked to indicate their answers on a 4-point scale $(1=$ no, 2 $=$ probably no, $3=$ probably yes, $4=$ yes). The alpha coefficients of the scores of these 12 items were .89 and .80 for the pretest and posttest, respectively. The average of the 12 scores was used to indicate how much the students accepted their peers with learning difficulties in doing things together.

Affective acceptance. This was measured by nine items from the affective component of the revised version of the Chedoke-McMaster Attitudes toward Children with Handicaps (Armstrong, 1986). These nine items measured the students' affective reaction to their peers with learning difficulties (e.g., "I would be pleased if they invited me to their house"). The alpha coefficients of the scores of these nine items were .92 and .90 for the pretest and posttest, respectively. The average of the nine scores was used to indicate how much the students accepted their peers with positive affect.

Donation. In the post program questionnaire, the students were asked how they would choose the cause for a fundraising activity in their schools. They were told that they could choose from four options: 1) The fund will be used to buy books for their school library; 2) The fund will be used to arrange tutoring services for students with learning difficulties; 3) The fund will be used to upgrade the computer facilities in 
their school; and 4) The fund will be used to install solar panels on the roof top of their school. They were asked to pick the cause that they wished to fund the most and that they would go home to ask their parents to sponsor. If they selected Option 2 as the cause for the donation, this would reflect their effort in helping students with learning difficulties.

Teaching quality. To check whether the teaching quality across the four classrooms was good and similar, the students were asked to rate the teaching on six statements (e.g., "the drama activities were helpful to my learning”). The student indicated their rating on a 4-point scale ( 1 = strongly disagree, $4=$ strongly agree). The alpha coefficient of the scores of these six items was .84. The average of the six scores was used to indicate the student evaluation of the teaching quality.

\section{Analysis Strategies}

Before the main analyses, preliminary analyses were conducted to examine whether the intervention was delivered equally well across the four classrooms, one-sample $t$ - test and one-way ANOVA were conducted on the student ratings of teaching quality. Second, independent $t$-tests were performed to rule out pre-program differences between the two conditions in the relevant measures. After these preliminary analyses were completed, we proceeded to the main analyses. To address the first research objective, correlation tests were run to examine the associations between classroom goals and the measures of peer acceptance. To address the second research objective, the program effects on peer acceptance were examined by ANCOVA with pre-program measures as covariates and the two conditions as between-subject variable. In addition, the differences between the two conditions in the intention to make donation were examined with Chi Square test.

\section{Results}




\section{Teaching quality}

The students’ average rating of teaching quality was $3.59(S D=.49)$. It was significantly different from the mid-point of the rating scale, $t=20.46, d f=85, p$ $<.001$. The results indicated that the students agreed that the teaching quality was good. To check whether the teaching quality varied across the four classrooms, a one-way ANOVA was conducted. The results indicated that there was no significant difference in teaching quality across the four classrooms, $F(3,82)=1.42, p=.24$.

\section{Pre-Program Descriptive Statistics}

Table 1 presents the descriptive statistics of all the variables measured before the program was implemented. To check whether the two conditions were similar on these variables, $t$-tests were performed. None of the results was significant ( $p s>.05$ ). Before the program, the two conditions were not different in the perception of classroom performance approach goals $\left(M_{\text {experimental }}=2.77, S D=.65 ; M_{\text {control }}=2.76\right.$, $S D=.58 ; t=.10, d f=84, p=.92$ ), classroom performance avoidance goals $\left(M_{\text {experimental }}=2.34, \mathrm{SD}=.62 ; M_{\text {control }}=2.20, S D=.58 ; t=.97, d f=84, p=.33\right)$, behavioral acceptance $\left(M_{\text {experimental }}=2.67, S D=.74 ; M_{\text {control }}=2.77, S D=.71 ; t=-.67\right.$, $d f=84, p=.49)$ and affective acceptance $\left(M_{\text {experimental }}=2.71, S D=.82 ; M_{\text {control }}=2.84\right.$, $S D=.88 ; t=.70, d f=84, p=.49$ ) to peers with learning disabilities.

(Insert Table 1 about here)

\section{Classroom Goal Orientation}

Table 1 also presents the correlations of the variables in this study before the program was implemented. It is noted that perception of classroom performance-approach goals was negatively correlated with behavioral acceptance, $r$ $=-.33, p=.002$. The more the students perceived that their classroom was 
performance-approach oriented, the less they would accept their peers with learning difficulties in doing things together.

\section{Program Effects on Behavioral Acceptance}

To test the program effects on behavioral acceptance, an ANCOVA was conducted to test the between-condition difference in the posttest behavioral acceptance with the pretest behavioral acceptance, classroom performance-approach goals, and performance-avoidance goals as covariates. As shown in Table 2, the two conditions were not significantly different from each other in the posttest, $F(1,81)$ $=.26, p=.61$, partial $\eta^{2}=.003$. The results indicated that the program did not have any effects on how much the students would accept their peers with learning disabilities in doing things together.

(Insert Table 2 about here)

\section{Program Effect Affective Acceptance}

To test the program effects on affective acceptance, an ANCOVA was conducted to test the between-condition difference in posttest affective acceptance with the pretest affective acceptance, classroom performance-approach goals, and performance-avoidance goals as covariates. As shown in Table 2, the two conditions were significantly different from each other at the posttest, $F(1,81)=4.60, p=.04$, partial $\eta^{2}=.054$. Compared to their counterparts in the control condition, the students in the experimental condition were more likely to have a positive affective reaction to their peers with learning disabilities after the program.

\section{Donation}

The choices of the students regarding the cause for the donation are presented in Table 3. Twenty-three students from the experimental condition indicated that they would like to use the fund to help students with learning disabilities to pay for 
tutoring services. In contrast, only two students from the control condition indicated that they would do so. The difference between the two conditions in the choice of this option was significant, $\chi^{2}=22.23, d f=1, p<.001$. This indicates that compared to their counterparts in the control condition, the students in the experimental condition were more likely to help their peers with learning disabilities after they had participated in the program.

(Insert Table 3 about here)

\section{Discussion}

The current study provides empirical evidence on how classroom goal orientation is related to students' acceptance of their peers with learning difficulties. Particularly when students perceive their classroom as having a strong focus on demonstrating their competence and outperforming others, they are less likely to accept their peers with learning difficulties. In addition, it showed that students' acceptance of and support toward those peers could be changed through a storytelling intervention with drama techniques.

In the current study, storytelling and drama techniques were combined to enhance students’ acceptance of children with learning differences. The results support the view that storytelling with drama techniques can change children's affective acceptance of peers with learning difficulties. While children are guided to engage in the story world, they may experience changes in attitudes (Adomat, 2012; Martinez \& Carspecken, 2006; Wright, Diener, \& Kemp, 2013).

\section{Classroom Goal Orientation}

The finding of the association between perceived classroom goal orientation and acceptance of students with learning difficulties fits into the emerging literature on the social impact of achievement goals. In a review paper, Poortvliet and Darnon 
(2010) concluded that performance goal orientation promotes maladaptive social behaviors while mastery goal orientation leads to more adaptive social behaviors such as investments in relationships, and active efforts to integrate different opinions. Mastery goal orientation involves the aim of improving one’s performance and task mastery. Since it is self-referenced, the performance of other students would be less of a concern to them. Therefore, the promotion of mastery goals would be a reasonable alternative to the promotion of performance goals in inclusive classrooms.

However, a caveat must be voiced about the extent to which mastery goals can improve the acceptance of peers with learning difficulties. Poortvliet, Janssen, Van Yperen, and Van de Vliert (2009) found that high ability students are less motivated to collaborate with other students regardless of their goal orientation. A possible explanation is that competent individuals feel that they are self-sufficient. Therefore, it is possible that even in a mastery-oriented classroom, students might not be motivated to work with students with learning difficulties because they might not find it beneficial to them or they might even be afraid that these students will slow down the learning progress of the class. Future research on the impact of a mastery-oriented classroom will be crucial for teachers in terms of what kind of atmosphere should be created for an inclusive classroom.

\section{Affective vs. Behavioral Acceptance}

Our results showed that students' affective acceptance of peers with learning difficulties was changed after the intervention. In particular, they were not afraid of having these students around and were happy to be around them. However, we did not find a significant difference in behavioral acceptance between the experimental condition and the control condition. This discrepancy may be due to the fact that the intervention focused on attitudinal change per se instead of skills acquisition. Students 
were taught that it will be enjoyable to befriend peers with learning difficulties. However, they might not be confident in how they should interact with or support those peers. This sense of inadequacy could hold students back from wanting to interact with them. In the broader helping literature, competence was found to be a key factor that predicts aiding behaviors (De Zeeuw, 2003). People are only willing to volunteer help as long as they feel competent in doing so. The current results provided further support for this such that students were willing to make donations to peers with learning difficulties but not willing to interact directly with them. In other words, students would like to support their peers in ways that are within their capacity. Therefore, effective interventions should not only focus on attitudinal change but also equip students with the skills to competently interact with peers with learning difficulties in order to promote behavioral change.

Another possible explanation for this discrepancy is that the performance goal orientation of the classroom might override students' willingness to interact with peers with learning difficulties. Participants in the experimental group understand that they should not be afraid to interact with those peers. However, they might not be willing to take action to interact with them because collaborating with them in school tasks could negatively affect their grades. This could be a particular concern if the classroom has a strong evaluative focus and competitive environment. Within a classroom with performance goal orientation, students might still decide to stay away from peers with learning difficulties even though their affective response says otherwise. As a future direction, the same experiment could be rerun in less competitive classrooms or cultures and examine if the intervention will result in behavioral change.

\section{Future Directions of Storytelling Programs with Drama Techniques}


One possible avenue is to understand the process of how the intervention would bring about attitudinal change. The design of the current storytelling intervention together with drama techniques was based on the assumption that students would be able to see things through the perspective of their peers with learning difficulties. As a result, students might become empathic toward those peers, leading to change in attitude and behaviors toward them. In a meta-analysis of more than 500 studies, Pettigrew and Tropp (2008) found that empathy had strong mediation value that accounted for the positive association between intergroup contact and prejudice reduction. However, we did not include a measure of empathy and so this mediation mechanism remains to be tested in future studies. Nonetheless, the current results could also be explained by other processes. For example, students could be merely modeling themselves after the characters in the stories without empathizing and understanding the circumstances. Another possible process might involve demand characteristics. Students could have guessed that the purpose of the experiment was to accept peers with learning difficulties and responded in a way that confirms this. If students' attitudinal change was due to the latter two reasons, the effect of the intervention might not be as long-lasting. Therefore, it is important to investigate the processes underlying the current findings.

While the current intervention showed promising effects, it is important to compare it with other interventions. As discussed in the literature review, Siperstein et al. (2011) suggested three common intervention approaches to changing students’ attitudes. These are teacher-directed instruction about disabilities, structured contact through third-party facilitation such as cooperative groupings and buddy programs, and combined instruction with structured contact. Future evaluation studies could be 
conducted to compare the current intervention with a more traditional approach on their effectiveness, costs, teachers' satisfaction and ease of learning.

In the current study, storybook telling with drama techniques was shown to be effective in improving inclusive education, particularly in accepting students with learning difficulties. It remains to be examined whether similar interventions could be utilized to address attitudinal changes in accepting other social groups that are often being discriminated against, for example, racial and religious minorities, and people with physical disabilities. We believe such an intervention is effective in helping students to put themselves into others' shoes, particularly with the addition of the drama approach. Future research of storytelling with drama techniques could be generalized to other domains.

Before closing, there are several limitations that should be considered. First, the results were based on a single experimental study. Therefore, future replication work should be conducted to test for the reliability of the results. Second, the current study was conducted with one age group only. Future studies could extend the sampling population to lower and higher grades to understand how well the current effects could be generalized to other age groups. Third, we did not include a measure of empathy. Future studies could include such a measure so as to investigate the mediation value of empathy. Fourth, the intervention consisted of two components, namely storytelling and drama. It was not clear which or if both components were operative. Future studies may undertake component analysis to determine whether similar effects could have been obtained using only storytelling or only drama. Lastly, our outcome variables were mainly measured by self-report. Although we utilized a donation question as a behavioral measure, it will be important to collect more 
behavioral data. For example, researchers can observe how the students are treating peers with learning difficulties in the classroom after the intervention.

\section{Conclusion}

To our best knowledge, this is the first study that evaluates the effectiveness of a storybook intervention that incorporates drama techniques which targets a change in students' acceptance of peers with learning difficulties. The success of inclusive education depends on both the acceptance and the social support from teachers and students. The current findings demonstrate a promising first step. We encourage other researchers to join our effort to develop an effective intervention program for inclusive education. 


\section{References}

Adomat, D. S. (2012). Drama’s potential for deepening young children’s understandings of stories. Early Childhood Education Journal, 40, 343-350. doi:10.1007/s10643-012-0519-8

Armstrong, R. W. (1986). Attitudes toward disabled children: A new measure. Open Access Dissertations and Theses. Retrieved from http://digitalcommons. mcmaster.ca/opendissertations/1171

Baldwin, P., \& Fleming, K. (2003). Teaching literacy through drama. London: Routledge Falmer.

Benninga, J. S., Tracz, S. M., Sparks, R. K., Solomon, D., Battistich, V. Delucchi, K. L., ... Stanley, B. (1991). Effects of two contrasting school task and incentive structures on children's social development. The Elementary School Journal, 92, 149-167.

Brady, K., \& Woolfson, L. (2008). What teacher factors influence their attributions for children's difficulties in learning? British Journal of Educational Psychology, 78, 527-544. doi:10.1348/000709907X268570

Brislin, R. W. (1970). Back-translation for cross-cultural research. Journal of Cross Cultural Psychology, 1, 185-216.

de Boer, A., Pijl, S. J., \& Minnaert, A. (2012). Students’ attitudes towards peers with disabilities: A review of the literature. International Journal of Disability, Development and Education, 59, 379-392. doi:10.1080/1034912X.2012. 723944

de Boer, A., Pijl, S. J., Minnaert, A., \& Post, W. (2014). Evaluating the effectiveness of an intervention program to influence attitudes of students towards peers with disabilities. Journal of Autism and Developmental Disorders, 44, 
572-583. doi:10.1007/s10803-013-1908-6

De Zeeuw, G. (2003). Helping others: Project or research? Journal of Community \& Applied Social Psychology, 13, 496-503.

Dunn, J., \& Stinson, M. (2012). Learning through emotion: Moving the affective in from the margins. International Journal of Early Childhood, 44, 203-218. doi:10.1007/s13158-012-0058-X

Edmiston, B. (2000). Drama as ethical education. Research in Drama Education: The Journal of Applied Theatre and Performance, 5, 63-84. doi:10.1080/ 135697800114203

Forlin, C., \& Cole, P. (1994). Attributions of the social acceptance and integration of children with mild intellectual disability. Australia and New Zealand Journal of Developmental Disabilities, 19, 11-23.

Frostad, P., \& Pijl, S. J. (2007). Does being friendly help in making friends? The relation between the social position and social skills of pupils with special needs in mainstream education. European Journal of Special Needs Education, 22, 15-30. doi:10.1080/08856250601082224

Georgiadi, M., Kalyva, E., Kourkoutas, E., \& Tsakiris, V. (2012). Young children’s attitudes toward peers with intellectual disabilities: Effect of the type of school. Journal of Applied Research in Intellectual Disabilities, 25, 531-541. doi:10.1111/j.1468-3148.2012.00699.x

Kardash, C. A. M., \& Wright, L. (1986). Does creative drama benefit elementary school students? A meta-analysis. Youth Theatre Journal, 1, 11-18.

Koster, M., Nakken, H., Pijl, S. J., \& van Houten, E. (2009). Being part of the peer group: A literature study focusing on the social dimension of inclusion in education. International Journal of Inclusive Education, 13, 117-140. 
doi:10.1080/13603110701284680

Lam, S.-f., Yim, P.-s., Law, J. S. F., \& Cheung, R. W. Y. (2004). The effects of competition on achievement motivation in Chinese classrooms. British Journal of Educational Psychology, 74, 281-296. doi:10.1348/ 000709904773839888

Lindsay, G. (2003). Inclusive education: A critical perspective. British Journal of Special Education, 30, 3-12. doi:10.1111/1467-8527.00275

Lindsay, G. (2007). Educational psychology and the effectiveness of inclusive education/mainstreaming. British Journal of Educational Psychology, 77, 1-24. doi:10.1348/000709906X156881

Lindsay, S., \& Edwards, A. (2013). A systematic review of disability awareness interventions for children and youth. Disability and Rehabilitation, 35, 623-646. doi: 10.3109/09638288.2012.702850

Liu, P. (2003). Transition from elementary to middle school and change in motivation: An examination of Chinese students. Journal of Research in Childhood Education, 18, 71-83. doi:10.1080/02568540309595023

Martinez, R. S., \& Carspecken, P. (2006). Effectiveness of a brief intervention on Latino children's social acceptance of peers with special needs. Journal of Applied School Psychology, 23, 97-115. doi:10.1300/J370v23n01_05

McDrury, J. \& Alterio, M. (2003). Learning through storytelling in higher education: Using reflection and experience to improve learning. London: Kogan Page.

McKee, R. (2003). Storytelling that moves people: A conversation with screenwriting coach, Robert McKee. Harvard Business Review, 80, 51-55.

Midgley, C., Maehr, M. L., Hruda, L. Z., Anderman, E., Anderman, L., Freeman, K, ... Urdan, T. (2000). Manual for the patterns of adaptive learning scales. 
Ann Arbor: University of Michigan.

Morgan, H. (2009). Picture book biographies for young children: A way to teach multiple perspectives. Early Childhood Education Journal, 37, 219-227. doi:10.1007/s10643-009-0339-7

Murayama, K., \& Elliot, A. J. (2012). The competition-performance relation: A meta-analytic review and test of the opposing processes model of competition and performance. Psychological Bulletin, 138, 1035-1070. doi:10.1037/a0028324

Neelands, J., \& Goode, T. (2000). Structuring drama work : A handbook of available forms in theatre and drama (2nd ed.). Cambridge: Cambridge University Press.

Norwich, B., \& Ylonen, A. (2013). Design based research to develop the teaching of pupils with moderate learning difficulties (MLD): Evaluating lesson study in terms of pupil, teacher and school outcomes. Teaching and Teacher Education, 34, 162-173. doi:10.1016/j.tate.2013.04.012

Nowicki, E. A. (2003). A meta-analysis of the social competence of children with learning disabilities compared to classmates of low and average to high achievement. Learning Disability Quarterly, 26, 171-188. doi:10.2307/ 1593650

Obiakor, F. E., Harris, M., Mutua, K., Rotatori, A., \& Algozzine, B. (2012). Making inclusion work in general education classrooms. Education \& Treatment of Children, 35, 477-490. doi:10.1353/etc.2012.0020

Ostrosky, M. M., Mouzourou, C., Dorsey, E. A., Favazza, P. C., \& Leboeuf, L. M. (2015). Pick a book, any book: Using children’s books to support positive attitudes toward peers with disabilities. Young Exceptional Children, 18, 
30-43. doi:10.1177/1096250613512666.

Pettigrew, T. F., \& Tropp, L. R. (2008). How does intergroup contact reduce prejudice? Meta-analytic tests of three mediators. European Journal of Social Psychology, 38, 922-934. doi.10.1002/ejsp.504

Pijl, S. J., \& Frostad, P. (2010). Peer acceptance and self-concept of students with disabilities in regular education. European Journal of Special Needs Education, 25, 93-105. doi:10.1080/08856250903450947

Poon-McBrayer, K. F. (2004). To integrate or not to integrate: Systemic dilemmas in Hong Kong. Journal of Special Education, 37, 249-256.

Poortvliet, P. M., \& Darnon, C. (2010). Toward a more social understanding of achievement goals: The interpersonal effects of mastery and performance goals. Current Directions in Psychological Science, 19, 324-328. doi:10.1177/ 0963721410383246

Poortvliet, P. M., Janssen, O., Van Yperen, N. W., \& Van de Vliert, E. (2009). Low ranks make the difference: How achievement goals and ranking information affect cooperation intentions. Journal of Experimental Social Psychology, 45, 1144-1147. doi:10.1016/j.jesp.2009.06.013

Read, C. (2008). Scaffolding children's learning through story and drama. IATEFL Young Learners, 2, 6-9.

Rutland, A., \& Killen, M. (2015). A developmental science approach to reducing prejudice and social exclusion: Intergroup processes, social-cognitive development, and moral reasoning. Social Issues and Policy Review, 9, 121-154.

Salend, S. J. (2011). Creating inclusive classrooms: Effective and reflective practices (7th ed.). Boston, MA: Pearson. 
Schwamborn, A., Thillmann, H., Opfermann, M., \& Leutner, D. (2011). Cognitive load and instructionally supported learning with provided and learner-generated visualizations. Computers in Human Behavior, 27, 89-93. doi:10.1016/j.chb.2010.05.028

Shuman, A. (2006). Entitlement and empathy in personal narrative. Narrative Inquiry, 16, 148-155. doi:10.1075/ni.16.1.19shu

Siperstein, G. N., Norins, J., \& Mohler, A. (2007). Social acceptance and attitude change: Fifty years of research. New York, NY: Springer.

Siperstein, G. N., Parker, R. C., Norins, J. B., \& Widaman, K. F. (2007). A national study of youth attitudes toward the inclusion of students with intellectual disabilities. Exceptional Children, 73, 435-455.

Siperstein, G. N., Parker, R. C., Norins, J., \& Widaman, K. F. (2011). A national study of Chinese youths' attitudes towards students with intellectual disabilities. Journal of Intellectual Disability Research, 55, 370-384. doi:10.1111/j.1365-2788.2011.01382.x

Smiley, J. (2005). Thirteen ways of looking at the novel. New York, NY: Random House.

Vaughn, S., \& Hogan, A. (1994). The social competence of students with learning disabilities over time: A within-individual examination. Journal of Learning Disabilities, 27, 292-303. doi:10.1177/002221949402700505

Watkins, D. A., \& Biggs, J. (Eds.) (1996). The Chinese learner: Cultural, psychological, and contextual influences. Hong Kong: Comparative Education Research Centre.

Winston, J. (1999). Theorising drama as moral education. Journal of Moral Education, 28, 459-471. doi:10.1080/030572499103016 
Wright, C., Diener, M. L., \& Kemp, J. L. (2013). Storytelling dramas as a community building activity in an early childhood classroom. Early Childhood Education Journal, 41, 197-210. doi:10.1007/s10643-012-0544-7 
Table 1

The Means and Correlations of Perceived Classroom Goals and Attitudes towards Students with Learning Difficulties before the Program

$\begin{array}{lllll}\text { Mean } & 1 & 2 & 3 & 4\end{array}$

(SD)

\begin{tabular}{llllll}
\hline 1.Performance-Approach Goals & 2.77 & -- & & \\
& $(.61)$ & & & \\
2.Performance-Avoidance Goals & 2.28 & $.54^{* *}$ & -- & \\
& $(.65)$ & & & & \\
3.Behavioral Acceptance & 2.72 & $-.33^{* *}$ & -.17 & -- \\
& $(.72)$ & & & & \\
4.Affective Acceptance & 2.77 & -.16 & -.04 & $.71^{* *}$ & -- \\
& & & & & \\
\end{tabular}


Table 2

Behavioral and Affective Acceptance of Peers with Learning Difficulties across the Two Conditions in the Pretest and Posttest

\begin{tabular}{lccccc}
\hline & \multicolumn{3}{c}{ Pretest } & & \multicolumn{2}{c}{ Posttest } \\
\cline { 2 - 3 } & Experimental & Control & Experimental & Control \\
& $(\mathrm{n}=45)$ & $(\mathrm{n}=41)$ & $(\mathrm{n}=45)$ & $(\mathrm{n}=41)$ \\
\hline Behavioral Acceptance & 2.67 & 2.77 & 2.53 & 2.70 \\
Affective Acceptance & $(.74)$ & $(.71)$ & $(.84)$ & $(.97)$ \\
& 2.71 & 2.84 & $2.84^{\mathrm{a}}$ & $2.66^{\mathrm{a}}$ \\
& $(.82)$ & $(.88)$ & $(.76)$ & $(.87)$ \\
\hline
\end{tabular}

Note. Means with the same superscript are significantly different from each other at .05 level. Numbers in parentheses are standard deviations. 
Table 3

The Number of Students by the Four Choices in Donation across the Two Conditions

\begin{tabular}{lll}
\hline Causes & Experimental & Control
\end{tabular}

$$
(n=45) \quad(n=41)
$$

Books

21

Tutoring Services

23

2

Computers

12

4

Solar Panels

8

34 


\section{Appendix 1}

Books read in the experimental condition:

1. Hudson, E. (2010). Hudson hates school (Q. Y. Liu, Trans., 2010). Taipei: 3 \& 3 International Education Institute.

2. Li, J. T. (2009). Sange haizi de gushi [The story of three children]. Taipei: Linking Publishing Company.

3. Polacco, P. (1998). Thank you, Mr. Falker (F. Ding, Trans., 2008). Taipei: Heryin Publishing Corporation.

4. Zhang, X. L. (2009). Duoduomao Dawang [The king of hide and seek]. Taipei: Hsin Yi Publications.

Books read in the control condition:

1. Okimoto, J. D. (2007). Winston of Churchill: One bear's battle against global warming (X. H. Lu, Trans., 2011). Taipei: Youth Culture Enterprise.

2. Park. K.-y. (2010). Clean energy: the sun, wind and water (L. R. Chen, Trans., 2012). Taiwan: Shang-Ren Publishing Company.

3. Liu, K. L. (2011). Kaixin nongchang: Zenme chi jiankang you huanbao? [Happy farm: How to be healthy and environmentally friendly in eating?]. Taipei: Grimm Press.

4. Burningham, J. (1999). Whadayamean (Z. M. Lin, Trans., 2003). Taipei: Yuan-Liou Publishing Company. 